\title{
El palacio fuera de palacio: prácticas arquitectónicas y festivas en jardines históricos y literarios de la temprana Edad Moderna
}

\author{
María del Rosario Aguilar Perdomo \\ Universidad Nacional de Colombia \\ Departamento de Literatura \\ mdaguilarp@unal.edu.co
}

\section{RESUMEN}

La importancia que paulatinamente va cobrando el jardín como espacio de divertimento cortesano en la sociedad española del siglo XVI, evidente en los palacios reales y nobiliarios, se manifiesta también en los libros de caballerías. El género, imbuido en las pautas culturales y estéticas del Quinientos, retrata a su vez las prácticas festivas de la nobleza cortesana que en la España de la época ocupó parte de sus tiempos de ocio con ceremonias y festejos desarrollados en este entorno natural. Este trabajo quiere mostrar que la posesión de un jardín de palacio puede ser considerada como una práctica arquitectónica de la más alta nobleza cortesana, que usó a su vez este espacio para sus prácticas festivas. Se revisan entonces diversos documentos y testimonios que evidencian los vínculos entre los oficios arquitectónicos y las celebraciones festivas de la nobleza cortesana en jardines, tanto literarios como históricos.

Palabras clave: Libros de caballerías españoles, jardines históricos, jardines literarios, prácticas arquitectónicas y festivas, nobleza cortesana.

\section{The palace outside the palace: architectural and festive performances in historic and literary gardens from the Early Modern Age}

\begin{abstract}
The importance gardens are gradually gaining as courtly entertainment space in 16th century Spanish society, evident in the royal and noble palaces, is also reflected in the books of chivalry. This genre, pervaded by cultural and aesthetic patterns of sixteenth century, portrays Spanish court nobility festive practices that devoted part of their leisure time to ceremonies and celebrations developed in this natural setting. This paper seeks to show that the possession of a palace garden can be considered an architectural practice among the highest court nobility, who used this space for festive practices. It takes in consideration several documents and evidences that show the links between architectural practices and festive celebrations of the court nobility in gardens, both literary and historical.
\end{abstract}

Key words: Spanish Romances of Chivalry, historic gardens, literary gardens, architectural and festal practices, courtly nobility. 
"Anduvieron un buen rato por las praderías del jardín, que son muy hermosas, [...] que cierto al parecer parescía que se hallaban en algo de lo que habian leído en los libros de caballerías, según se les representó aquella hermosura de fuentes,

y maravillosos arroyos vertientes, $y$ diversidades de olorosas flores y árboles, y otras lindezas de verduras"

Andrés Muñoz, Sumaria y verdadera relación del buen viaje que el príncipe Felipe hizo a Inglaterra

$$
\begin{array}{r}
\text { “Ó, señor primo! ¡Y en qué tranquilidad } \\
\text { traemos el ánimo y los sentidos después } \\
\text { de llegados a Monforte! Plantamos } \\
\text { jardines y edificamos la habitación del Monte”. } \\
\text { Carta del Conde de Lemos al príncipe } \\
\text { de Esquilache, } 15 \text { de marzo de } 1619
\end{array}
$$

Como ocurrió con otras prácticas culturales, la posesión de un jardín en palacio fue también a finales de la Edad Media y en los años del Renacimiento una muestra de la magnificencia de los soberanos y sus nobles, que, en algunas ocasiones, emulando a sus monarcas o a sus antepasados replicaban sus gustos, aficiones y hazañas arquitectónicas. En este terreno, los jardines fueron ya desde finales del siglo XV un polo importante de la arquitectura civil española que contribuyeron a la reafirmación de una conciencia nobiliaria y la representación de un estamento social. Símbolos elocuentes de poder, prestigio y distinción, estos espacios señoriales fueron construyéndose en algunos casos, y readecuándose en otros, sobre las bases de los jardines hispanomusulmanes, y de la mano de los nuevos gustos y la progresiva ascendencia de las modas flamencas, francesas e italianas en la cultura nobiliaria y cortesana de la temprana Edad Moderna, cuando se produjeron una serie de intervenciones arquitectónicas en propiedades representativas de los grandes linajes que dieron lugar a la transformación de los viejos castillos medievales en espléndidos y confortables recintos palaciegos ${ }^{1}$. Lugares de ocio, de conversación, de festejo y de encuentro amoroso, tal como lo transmite la imagen codificada que nos proporciona de ellos la literatura caballeresca y cortés desde los siglos XV y XVI, gracias a la cual es posible acercarse en parte a su conceptualización, los jardines se constituyeron en espacio

1 Piénsese por ejemplo en la transformación y renovación del castillo de los Benavente o de los Duques de Feria en Zafra bajo los nuevos criterios renacentistas, en la que se incluyen los jardines. Sobre la conformación de la ciudad y el palacio como espacios nobiliarios de representación del poder, en el que el jardín ocupa, desde mi punto de vista, un lugar significativo como muestra de un nuevo ideario y de nuevas prácticas culturales de la nobleza, puede consultarse el interesantísimo artículo de E. ALEGRE CARVAJAL, "La configuración de la ciudad nobiliaria en el Renacimiento como proyecto ideológico de una élite de poder", Tiempos modernos. Revista electrónica de Historia Moderna, 16 (2008), disponible en http://www.tiemposmodernos.org/tm3/ index.php/tm/issue/view/23 [última consulta 14 de febrero de 2013]. 
importante para unas élites nobiliarias dispuestas a simbolizar su poder y a manifestar sus intereses culturales en ese entorno vegetal cuyo valor había venido ascendiendo con el cambio de los gustos y las mentalidades.

En España los jardines nobiliarios de los palacios urbanos y casas de placer o quintas de recreo suburbanas, que configuran un contexto perdido como lo ha llamado Vicente Lleó Cañal ${ }^{2}$, nos remiten a la conformación no solo de un trazado jardinero compartido por un estamento social, sino también a la disposición de este espacio como un signo de identidad, como architectura parlante ${ }^{3}$, de una aristocracia cortesana que se había concienciado de la relevancia de la construcción entre los usos culturales propios de su estamento, y también como una actividad propicia para ejercer en tiempos de ocio ${ }^{4}$. En efecto, entre finales del siglo XV y a lo largo del XVI los gestos de la nobleza comienzan a desvelar el interés por el espacio del jardín como un palacio fuera del palacio donde, como señalaba anteriormente, se despliegan prácticas que desarrollan signos identitarios de una clase noble ${ }^{5}$ que, también en este aspecto, tuvo hábitos imitativos hacia los gustos de sus gobernantes ${ }^{6} \mathrm{o}$ de sus antepasados. En ese sentido, es relevadora la frase atribuida a doña Mencía de Mendoza, quien le había prometido a su esposo don Pedro Fernández de Velasco, II conde Haro y Condestable de Castilla, "una capilla donde orar, un palacio donde morar y una quinta donde holgar". Tanto su actividad constructora como la de su marido fue luego reconocida por su nieto, de igual nombre y IV Condestable de Castilla, que calificaba a su antepasado como

"amigo de edificar, y assí hiço una cassa de aposentamiento en la fortaleça de Villalpando y labró la casa de la Vega que es una casa de plaçer çerca de Burgos y hizo en la çiudad una cassa muy buena"’.

2 V. LLEÓ CAÑAL, "Un contexto perdido. Los jardines de la nobleza”, C. AÑÓN y J.L. SANCHO (eds.), Jardín y naturaleza en el reinado de Felipe II, Madrid, 1998, pp. 222-241.

3 Tomo el término que Vicente Lleó Cañal aplica al palacio y la villa suburbana. Desde mi punto de vista los jardines nobiliarios, como parte de estos, "entre otras funciones cumplieron la de informar sobre su dueño, sobre su estatus social, sobre su cultura, sobre sus afinidades espirituales", V. LLEÓ, Nueva Roma. Mitología y humanismo en el Renacimiento sevillano, Madrid, 2012, p. 82.

4 S. MARTÍNEZ HERNÁNDEZ, "Obras... que hazer para entretenerse: la arquitectura en la cultura nobiliario-cortesana del Siglo de Oro: a propósito del marqués de Velada y Francisco de Mora", Anuario del Departamento de Historia y Teoría del Arte, 15 (2003), pp. 59-77; y "Fragmentos de ocio nobiliario. Festejar en la cultura cortesana", B. GARCÍA y M.L. LOBATO (coords.), Dramaturgia festiva y cultura nobiliaria en el siglo de oro, Madrid/Frankfurt, 2007, pp. 45-88; F. BOUZA ÁLVAREZ, "Cortes festejantes, fiesta y ocio en el cursus honorum cortés", Manuscrits, 13 (1995), pp. 185-2003; y "Realeza, aristocracia, mecenazgo. [Del ejercicio del poder MODO CÁLAMO]", A. EGIDO y J.L. LAPLANA (eds.), Mecenazgo y humanidades en tiempos de Lastanosa, Zaragoza, 2008, pp. 69-88.

5 El jardín nobiliario fue también lugar idóneo para reunir, por ejemplo, colecciones escultóricas y galerías de pinturas, pequeños studioli al aire libre o jardines arqueológicos, como los ha denominado V. LLEÓ CAÑAL, op. cit., 1998.

6 No sólo la afición arquitectónica de Felipe II, también otras prácticas culturales, como los gustos literarios y la conformación de bibliotecas, tuvieron eco entre sus cortesanos. Así lo ha estudiado P.M. CÁTEDRA GARCÍA, Nobleza y lectura en tiempos de Felipe II. La biblioteca de don Alonso Osorio, Marqués de Astorga, Valladolid, 2002, p. 59.

7 Pedro Fernández de Velasco, Descendencia de la casa i linaje de Velasco, Biblioteca Nacional de Madrid (BNM), sig. Mss/2018, fols. 47-48. Del dinamismo arquitectónico del linaje se ha ocupado B. ALONSO 
Tampoco debe extrañar, en ese entorno de emulación edificadora, la frase incluida en una carta de Francisco de Zúñiga y Sotomayor, IV duque de Béjar, dirigida a Mateo Vázquez en 1580, después de su visita a Aranjuez: "Los que somos remedones presumimos como si entendiésemos de arquitectura" 8 , en referencia a los trabajos ordenados por Felipe II en el Real Sitio y, probablemente a sus propias aficiones constructoras. La aristocracia cortesana parecía compartir estas aficiones, al menos así lo insinúan los tempranos quehaceres arquitectónicos y jardineros de don Rodrigo Díaz de Vivar, hijo del Cardenal Mendoza y I marqués de Zenete en su baronía de Alcócer, donde se ocupó personalmente de las huertas y jardines de su casa palacio; las de Juan Alfonso Pérez de Guzmán, VI duque de Medina Sidonia, quien realizó mejoras en su palacio y jardín de Sanlúcar de Barrameda ${ }^{9}$, o las del propio duque de Béjar en su palacio y jardín del Bosque, construido en 1567. También don Martín de Guerra y Aragón, IV duque de Villahermosa, se interesó por los asuntos arquitectónicos de sus palacios y casa de placer; años antes el duque de Alcalá había ordenado hacer intervenciones a la italiana en la Casa Pilatos o en su palacio de Bornos, y, más tardíamente, don Gómez Dávila y Toledo, marqués de Velada ${ }^{10}$, trazó los planos de su jardín e incluso dio consejos a su amigo Pedro de Toledo, V marqués de Villafranca sobre el diseño del suyo en Bierzo ${ }^{11}$ (fig. 1).

RUIZ, "Palacios donde morar y quintas donde holgar de la Casa de Velasco durante el siglo XVI", Boletín del Museo e Instituto Camón Aznar, 83 (2001), pp. 5-33; B. ALONSO, M.C. DE CARLOS y F. PEREDA, Patronos y coleccionistas: los condestables de Castilla y el arte (siglos XV-XVII), Valladolid, 2005. Para el ámbito que nos interesa, es importante anotar que los Velasco también se ocuparon de los jardines en sus residencias nobiliarias.

8 Duque de Béjar a Mateo Vázquez de Leca, Madrid, 3 de abril de 1580, Instituto Valencia de Don Juan, Madrid, Envío 1 (2), 283, recogido por F. BOUZA, op. cit., 2008, p. 69. Conforme a esta caracterización habría que interpretar la construcción en 1567 por parte del IV duque de Béjar de una casa de placer con jardines y terrazas a la italiana.

9 Según Juan Pedro Velázquez Gaztelu, historiador relacionado con la casa de Medina Sidonia y regidor municipal de Sanlúcar, durante los años en que Juan Alonso de Guzmán vivió en el palacio se dedicó a las mejoras del palacio y de los jardines, "que fueron por tiempo de un siglo que lo disfrutaron sus dueños, la maravilla de estos contornos, según tradición de nuestros mayores", Historia antigua de la muy noble y muy leal ciudad de Sanlúcar de Barrameda escrita por don Juan Pedro Velázquez Gaztelu, regidor perpetuo de la misma ciudad, y su diputado archivista. Año de 1760, M. ROMERO (ed.), Sanlúcar de Barrameda, 1994, vol. II, p. 62 .

10 M. GÓMEZ-FERRER, "El Marqués de Zenete y sus posesiones valencianas. Mentalidad arquitectónica y artística de un noble del Renacimiento", Anuario del Departamento de Historia y Teoría del Arte, 22 (2010), pp. 27-46; J.A MOREJÓN, Nobleza y humanismo. Martín de Guerra y Aragón. La figura cultural del IV Duque de Villahermosa (1526-1581), Zaragoza, 2009; para las intervenciones arquitectónicas del Duque de Alcalá, V. LLEÓ CAÑAL, "El jardín arqueológico del primer Duque de Alcalá", Fragmentos, 11 (1987), pp. 21-32; y La Casa Pilatos, Madrid, 1998. Sobre el Marqués de Velada, S. MARTÍNEZ HERNÁNDEZ, op. cit., 2003.

11 Tal vez no demasiado lejos de estas labores arquitectónicas de la nobleza cortesana estarían las edificaciones que suelen salir de las manos de sabios y magos en los libros de caballerías; de hecho dos de ellos aluden a la construcción de jardines: "Y tomando todos sus libros y a Fidea con ellos, assió el cuerpo de Furión muerto y en un punto fue puesta en la alta roca que os diximos, haziendo dentro d'ella un palacio tan hermoso y tan rico que las paredes eran de jaspe y los pilares de cristales de muchos colores. Hizo dentro tantos jardines y fuentes que era muy grande espanto de ver, todas hechas de piedras de gran valor", Policisne de Boecia, E. SALES DASÍ (ed.), Alcalá de Henares, 2008, p. 82. Asimismo, en el Tristán de Leonís y el rey don Tristán el Joven, L.D. CUESTA (ed.), México, 1997, p. 821: "Y Sargia començó su obra apriessa, y la mitad de su exército andava labrando en la torre, y la mitad en los jardines. De manera que, cuando el sol salió, estava 


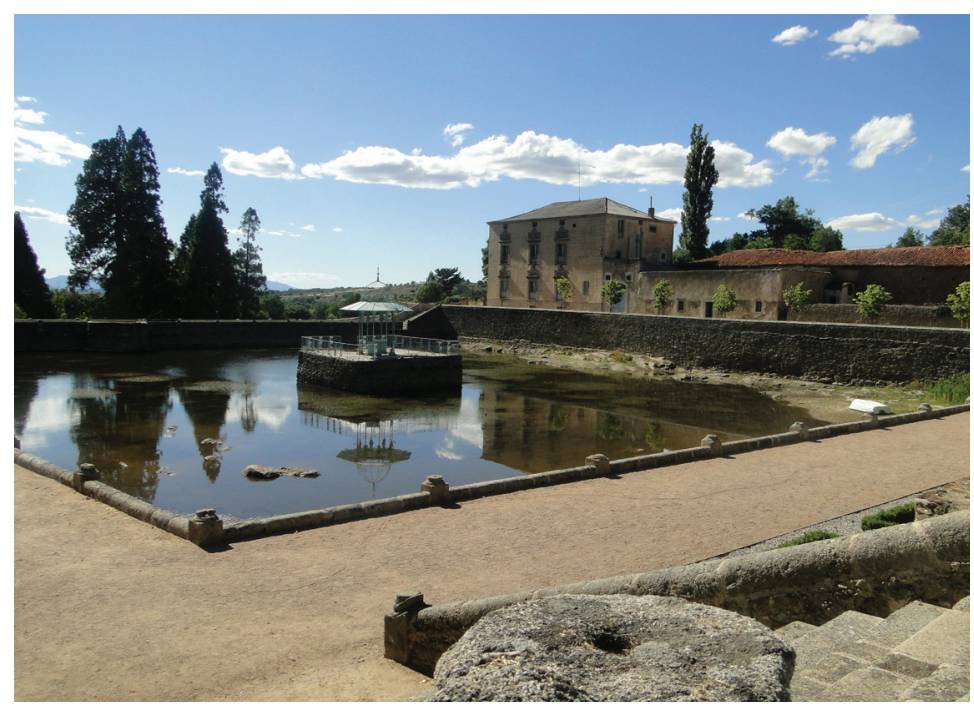

Fig. 1. Palacio y estanque del jardín del Bosque, Béjar.

Pareciera entonces que lo más granado de la nobleza cortesana buscó adecuar espacios estéticamente bellos donde fuera posible encontrar la alegrezza y la commoditá ${ }^{12}$, el gozo del festejo. Varios legajos históricos muestran que los estamentos más altos de la sociedad española del Antiguo Régimen disfrutaron, como veremos, de más de un sarao, un banquete o una merienda en el jardín como parte sus hábitos culturales $^{13}$, casi en la misma medida en la que la literatura caballeresca española del S. XVI, punto de partida de mi investigación, remite a la imagen del jardín como un espacio propicio para la recreación y al esparcimiento lúdico ${ }^{14}$. Preciosos fragmentos

la torre hecha de hermosa sillería, con muchas finiestras a todas partes; y el jardín edificado de un muro alto de sillería junto con el castillo, hazia la parte de la villa, que del castillo por una puerta pequeña se mandava, en el cual avía multitud de árboles de muchas frutas, y rosales y jazmines y yervas olorosas. Y a la parte alta del jardín estava un pilar grande de agua, que por XII caños el agua en él caía, y de allí se regava el jardín. Y sabed que los árboles estavan tan frescos como si allí uvieran sido nacidos, y muchos d'ellos cargados de fruta; y rosas y jazmines y otras flores que bien olían. Y assí mesmo amaneció hecho un pilar de agua dulce en mitad de la plaça, labrado de mármor blanco, con sus caños de agua muy gruessos que en él caían".

12 Lo señalaba así Juan de Mariñas en una carta del 21 de julio de 1600 al conde de Gondomar, Diego Sarmiento de Acuña, recogida por F. BOUZA, op.cit., 1995, p. 200.

13 La fiesta, por supuesto, es sólo uno de las actividades que ocupaba el ocio nobiliario, en el que se pueden incluir otros entretenimientos y aficiones como el coleccionismo, la lectura, y para lo que nos interesa, las trazas de jardines. Así lo plantea S. MARTÍNEZ HERNÁNDEZ, op. cit., 2007, p. 46.

14 La literatura caballeresca española proyecta fundamentalmente una representación del jardín como locus amoenus, como espacio propicio al amor y a la recreación de los sentidos. Así lo era ya en la tradición greco-latina, la del occidente medieval y también en la hispanoárabe. Y así lo continuará siendo en la de la temprana Edad Moderna. No es éste, sin embargo, el aspecto que quiero resaltar; me he ocupado de él en M.R. AGUILAR PERDOMO, "Espesuras y teximientos de jazmines: los jardines en los libros de caballerías españoles, entre lo medieval y lo renacentista", e-Humanista, 16 (2010), pp. 195-220, disponible en [http:// www.ehumanista.ucsb.edu/volumes/volume_16/index.shtml]. 
de este género pre-cervantino acreditan que este recinto vegetal fue también escenario para la fiesta y las celebraciones de la nobleza, cuyos ecos nos llegan desde los siglos XV, XVI y XVII, último siglo donde se produjo la consagración del jardín como recinto festivo y marco propicio para el desarrollo del teatro ${ }^{15}$. La relación de una fiesta de las primeras décadas del siglo XVII muestra con contundencia cómo el jardín de palacio continuaba siendo el escenario perfecto para el fasto cortesano y cómo en éste se mantenían los estrechos lazos - que se habían gestado desde fines de la Edad Media- con la literatura caballeresca como fuente de inspiración ${ }^{16}$. El 15 de mayo de 1622 se escenificaba en el Jardín de la Isla del palacio de Aranjuez la invención del conde de Villamediana, Juan de Tassis, titulada La gloria de Niquea como parte de los eventos para celebrar el cumpleaños del joven rey Felipe IV. Aunque el testimonio es tardío para la época que nos interesa -las primeras décadas de la Edad Moderna- es elocuente, sin duda, que la obra se inspire en uno de los ciclos caballerescos más importantes del siglo XVI, el de Amadís de Gaula y sus descendientes, en particular Amadis de Grecia y Florisel de Niquea ${ }^{17}$, que el escenario escogido haya sido el jardín del palacio de Aranjuez y que, adicionalmente, una de las escenas tuviera como trasfondo un jardín fingido, construido, un jardín artificial. Antonio Hurtado de Mendoza daba cuenta del suceso y del espectacular montaje en el que participó el escenógrafo napolitano Julio César Fontana ${ }^{18}$ y anotaba en su Relación que, al co-

15 Como fue también escenario de ocio para muchos nobles que cansados de las mezquindades de la corte querían refugiarse en su jardín. Lo recuerda F. BOUZA, "Entre cortesanos y discretos. Cultura nobiliaria y poder en la España de los Austrias", Imagen y propaganda. Capítulos de historia cultural del reinado de Felipe II, Madrid, 1998, pp. 199-210.

16 Los estudios sobre recibimientos y entradas triunfales y otros aspectos del fasto cortesano han demostrado la relación que se estableció desde el siglo XV entre la narrativa caballeresca y las manifestaciones festivas de los estamentos nobiliarios. De hecho, la caballería impregna todo lo que toca y se convierte en un referente metafórico que alimenta la ficción, a su vez que ésta inspiró, gracias al llamado effet roman, las celebraciones cortesanas que también tienen como escenario los jardines. La bibliografía al respecto es muy abundante a partir del precioso trabajo de M. DE RIQUER, Caballeros andantes españoles, Madrid, 1967. Entre otros, T. FERRER VALLS, Nobleza y espectáculo teatral (1535-1622), Valencia, 1993; A. DEL RÍO NOGUERAS, "Sobre magia y otros espectáculos cortesanos en los libros de caballerías", J. PAREDES (ed.), Medioevo y literatura. Actas del V Congreso de la Asociación Hispánica de Literatura Medieval, Granada, 1995, IV, pp. 137-149; y "Libros de caballerías y burlas cortesanas. Sobre algunos episodios del Cirongilio de Tracia y del Clarián de Landanís", J. GÓMEZ-MONTERO y B. KÖNIG (dirs.), Literatura caballeresca entre España e Italia (De "Orlando" al "Quijote"), Salamanca, 2004, pp. 53-65; M.C. MARÍN PINA, "Fiestas caballerescas aragonesas en la Edad Moderna", Fiestas públicas en Aragón en la Edad Moderna, Zaragoza, 1995, pp. 109-118. Para el effet roman son fundamentales M. STANESCO, Jeux d'errance du chevalier médiéval. Aspects ludiques de la fonction guerrière dans la littérature du Moyen Âge flamboyant, Leiden, 1998; P.M. CÁTEDRA GARCÍA, "Realidad, disfraz, e identidad caballeresca", E. CARRO, L. PUERTO y M. SÁNCHEZ (eds.), Libros de caballerías. De “Amadís " al "Quijote", Salamanca, 2002, pp. 71-85; y El sueño caballeresco. De la caballería de papel al sueño real de don Quijote, Madrid, 2007.

17 El Amadis de Grecia (1530) es el libro IX del ciclo de Amadís de Gaula; del Florisel de Niquea se publicaron tres partes. La dos primeras, impresas en 1532, conforman la entrega $\mathrm{X}$ de la saga amadisiana, mientras que la tercera (parte XI del ciclo) es de 1535. Todas estas continuaciones fueron escritas por el prolífico Feliciano de Silva. Ver, J.M. LUCÍA MEGÍAS y E. SALES DASÍ, Libros de caballerías castellanos (s. XVI-XVII), Madrid, 2008, p. 62.

18 No me detendré en la trama y la escenografía, esta última rigurosamente estudiada por M.T CHÁVES MONTOYA, La gloria de Niquea. Una invención en la corte de Felipe IV, Aranjuez, 1991; y "La escenografía del teatro cortesano", B. GARCÍA y M.L. LOBATO (coords.), Dramaturgia festiva y cultura nobiliaria en el siglo de oro, Madrid/Frankfurt, 2007, pp. 325-345. Del argumento y los vínculos de la invención con los 
menzar el segundo acto, el aparato ocupaba todo el escenario y estaba diseñado con la apariencia de una montaña:

"volvíase luego a abrir [...] al son de los instrumentos, y con novedad no esperada lo que fue monte, y edificio, vimos convertido en bellísimos jardines, con flores y fuentes naturales" $"$.

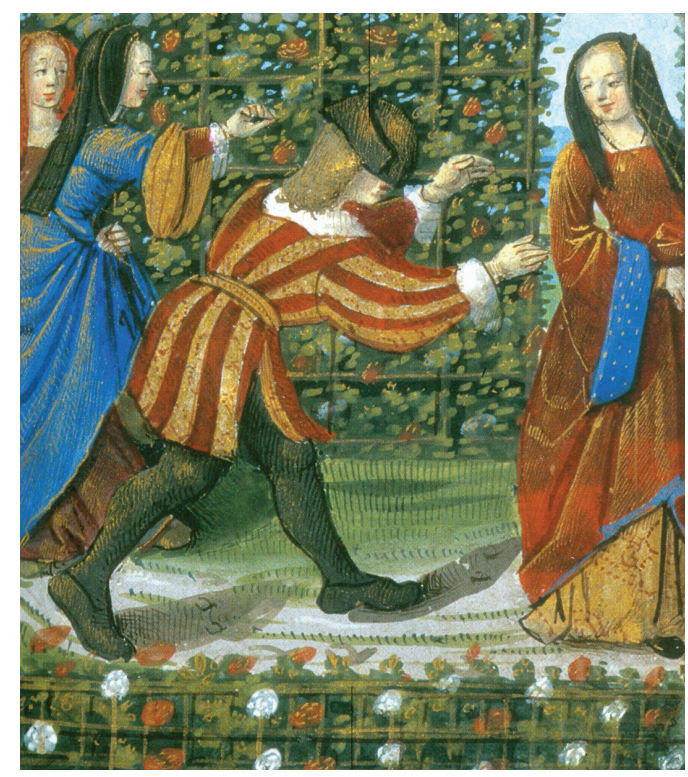

Fig. 2. Miniatura del manuscrito de Pierre Sala, Petite livre d'amour, f. 7r, British Library, Stowe, Mss. 955.

Ninguno de los aspectos que participa en la celebración en Aranjuez puede pasarse por alto, y, mucho menos, la construcción artificial de un jardín que sirve como trasfondo o escenario, que nos revela una determinada actitud estética ${ }^{20}$. Huellas de

libros de caballerías se ha ocupado E. BORREGO GUTIÉRREZ, "Libros de caballerías y fiestas cortesanas para el recién coronado Felipe IV", B. GARCÍA y M.L. LOBATO, Dramaturgia festiva y cultura nobiliaria en el siglo de oro, Madrid/Frankfurt, 2007, pp. 347-383. Sobre la aventura de la gloria de Niquea en el Amadís de Grecia, ver A.C. BUENO SERRANO, "Una ordalía mágico-amorosa en el Amadís de Grecia de Feliciano de Silva”, Voz y Letra, 18, 2 (2007), pp. 3-28. Para más bibliografía al respecto, consúltese la base de datos Clarisel (http://clarisel.unizar.es/), entrada "Gloria de Niquea".

19 Antonio Hurtado de Mendoza, Fiesta que se hizo en Aranjuez a los años del Rey nuestro señor don Felipe IV, Madrid, 1623, pp. 35-36.

20 De hecho, el levantamiento de jardines artificiales y efímeros fue muy del gusto de la estética del seiscientos y no sólo en España. Por ejemplo, en el Palacio real de Nápoles, con el auspicio del VII Conde de Lemos, el 1 de marzo de 1620 se llevó a cabo una fiesta para celebrar la recuperación de Felipe III. Para uno de los espectáculos, titulado Delizie di Posilipo Boscarecce e incluido en la Festa a Ballo, se construyó un jardín artificial como parte de la escenografía: "L'invenzione dell'apparato fu il delizioso monte di Posilipo, formandosi particularmente tutto di rilievo il Palazzo detto della Goletta e i suoi giardini, scogli, e grotte 
esos ejercicios artísticos en los entornos nobiliarios se encuentran, como veremos, en las dos laderas que me interesan: la histórica y la literaria, tanto en los jardines de la nobleza y la realeza como en los jardines literarios, los que podríamos llamar jardines de papel$^{21}$ (fig 2.).

A lo largo del siglo XVI, los jardines de palacios urbanos y suburbanos se convierten paulatinamente en espacios plenos de sentido lúdico. Se dotan de un nuevo sentido celebrativo y simbólico al adornarlos con decorados cuyos referentes en más de una oportunidad proceden de la estética y la temática caballeresca. Está claro que jardín, fiesta y caballería, esta última tanto en sus representaciones estamentales como en sus expresiones literarias, van de la mano durante estos años ${ }^{22}$. El espacio al aire libre se convierte, entonces, en escenario oportuno para espectáculos y celebraciones de todo tipo: banquetes, bailes, torneos, máscaras y burlas de agua -como las que se dispusieron en el jardín de los duques de Alba en Abadía- ${ }^{23}$ se ponen a la orden del día en las prácticas festivas de la nobleza. Los textos literarios y sus jardines de papel, así como los documentos históricos, descubren este hecho irrefutable, que ya refería Cristóbal de Villalón cuando señalaba el traslado de los pasatiempos cortesanos del espacio cerrado del palacio al recinto ajardinado al aire libre:

"Pues el día de hoy es entre los hombres en uso tan común entre qualesquiera condiçiones de varones en pasatiempos de convites o çenas que no pasan su tiempo en más para su conversación y plazer. Préçianse todos de se motejar entre sí y entre su hablar vienen a dezir motes y graçias sabrosas y apazibles, y a dezir cuentos, fábulas y façeçias, con las quales se quieren recrear, y principalmente quando el convite se ha çelerado en un deleitoso huerto o jardín, en el qual es lugar más aparejado para este género de recreaçión, como nos es agora a nosotros este" 24.

El jardín se convierte, entonces, siguiendo el hilo trazado por Villalón, en escenario de banquetes cuando los gustos y la conceptualización de ese constructo cultural se modifican. La definición de Alberti en su Re aedificatoria como un locus de la festivitas había resaltado ya la condición lúdica y festejante del jardín, que se correspondía a la vez con los intereses nobiliarios que veían en este espacio una manifestación

fuori [...] gode con mirabile artifitio tutto al naturale", Breve raeconto della Festa a Ballo. Fattasi a Napoli per 1 'allegrezza della salute acquistata della Maestd Cattolica di Filippo III D Austria Re delle Spagne, R. JACKSON (ed.), A Neapolitan Festa a Ballo and selected instrumental ensemble pieces, Madison, 1978, p. XIII; M.T. CHAVES MONTOYA, "La montaña en las fiestas de corte en Nápoles y Madrid durante el siglo XVII", Cuadernos de arte e iconografía, VI, 11 (1993), pp. 410-420.

21 Retomo este término, jardines de papel, del artículo de E. RODRÍGUEZ ROMERO, "Jardines de papel: la teoría y la tratadística del jardín en España durante el siglo XIX”, Asclepio, LI, 1 (1999), p. 129-158. Sin embargo, mientras la profesora Rodríguez lo utiliza para referirse a los tratados teóricos, yo lo empleo en alusión a los jardines descritos en textos literarios, relaciones de sucesos, relaciones topográficas, crónicas de viajeros y otros documentos. Así mismo es un eco del libro de P.M. CÁTEDRA, op. cit., 2007, quien agrupa la ficción caballeresca bajo el rótulo de caballería de papel.

22 Me he ocupado de este tema en "Jardim, festa e literatura cavaleiresca", M. MONGELLI (coord.), E fizerom taes marravilhas... Histórias de cavaleiros e cavalarias, Sao Paulo, 2012, pp. 365-384.

23 P. NAVASCUÉS PALACIO, "La Abadía de Cáceres: espejo literario de un jardín", Anuario del Departamento de Historia y Teoría del Arte, V (1993), pp. 71-90.

24 C. DE VILLALÓN, El Scholástico, J.M. MARTÍNEZ TORREJÓN (ed.), Barcelona, 1997, p. 322. 
simbólica del poder, un recurso para la ostentación de su condición y un lugar donde cohesionarse como estamento a través del ocio y la diversión ${ }^{25}$. Como ha apuntado Consuelo Gómez López, el jardín es marco festivo y, fundamentalmente, espacio cortesano $^{26}$ en el que los ceremoniales festivos implicaban una reafirmación de pertenencia a un estamento, una "muestra de cohesión de clase" como ocurría también con otras manifestaciones caballerescas (fig. 3.).

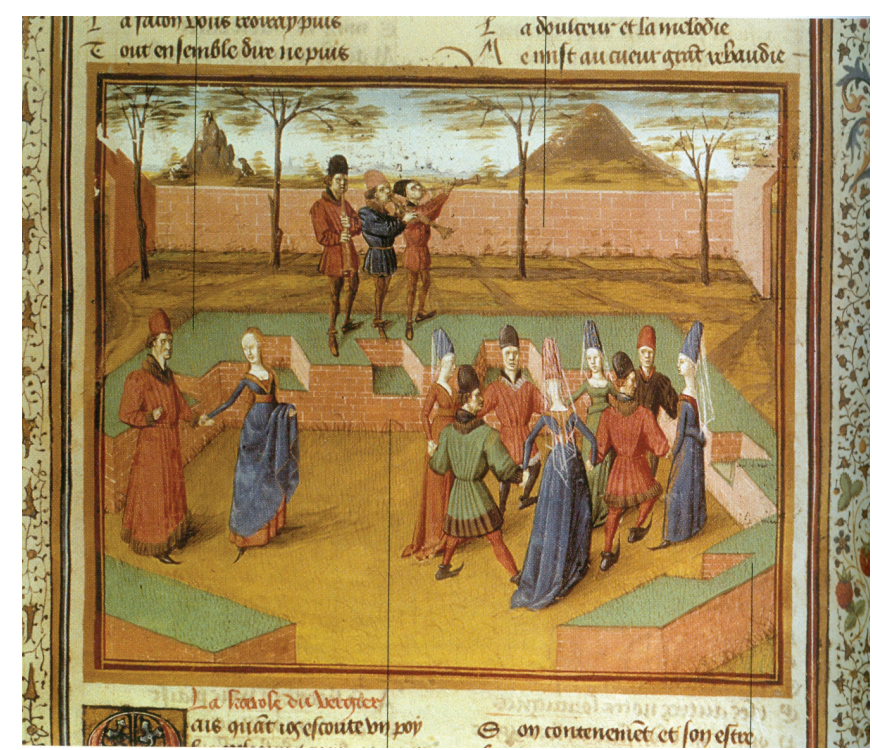

Fig. 3. Maestro de Jouvenel, Baile en jardín, BNF.

Acorde con esta conceptualización del jardín, los reyes y la nobleza de la temprana Edad Moderna se deleitaron en esta naturaleza acotada con más de un festejo o de un momento de descanso. Jerónimo Münzer relataba en la crónica de su viaje a España entre septiembre de 1494 y febrero de 1495, a propósito de la belleza de los jardines valencianos, que él y sus acompañantes se creían en "el Paraíso Terrenal" ${ }^{27}$. Resaltaba asimismo que para él no había "en el mundo morada más deleitosa" ${ }^{28}$ que el jardín del palacio del Cardenal Mendoza en Guadalajara, famoso por sus pajareras. El embajador Andrea Navagero, por su parte, consideraba en 1526 que el jardín del Alcázar de Sevilla, sembrado de naranjos y limoneros que impedían el paso del sol era "el sito

25 No hay que olvidar en este aspecto los planteamientos de N. ELIAS, La sociedad cortesana, México, 1983.

26 C. GÓMEZ LÓPEZ, "El gran teatro de la corte: naturaleza y artificio en las fiestas de los siglos XVI y XVII”, Espacio, Tiempo y Forma, 12 (1999), p. 201.

27 J. MÜNZER, "Relación del viaje”, J. GARCÍA MERCADAL (ed.), Viajes de extranjeros por España y Portugal, Madrid, 1952, p. 340

28 Ibid., p. 409. 
más apazible de España" ${ }^{29}$. En 1543, de camino a su encuentro con María de Portugal en Salamanca, el príncipe Felipe estuvo al menos dos noches descansando en Abadía (Cáceres) ${ }^{30}$, el jardín del duque de Alba exaltado por Luis de Zapata en su Miscelánea y descrito por Lope de Vega ${ }^{31}$. De hecho, se hicieron frecuentes las jornadas festivas en jardines durante los viajes reales, como lo deja entrever la crónica de Calvete de Estrella. Así, en 1548, en Barcelona, el príncipe Felipe y sus acompañantes disfrutaron del banquete que el cardenal de Trento ofreció en su honor en

"un jardín muy lleno de naranjos y cidros, y otros árboles muy diversos, donde para ello estava un cenador muy bien adereçado [...] Uvo a la noche fiestas y máscaras”32.

Es claro que hay pocos lugares como el jardín tan propicios al esparcimiento gracias a un proceso de alquimia cultural que permite diseñar la naturaleza al gusto y acorde con el cambio de las mentalidades. Lo experimentaron plenamente también los nobles en los jardines de sus palacios y casas de placer. No han quedado sino escasas huellas de uno de ellos, al parecer excepcional por lo que nos dicen los cronistas y escritores como Antonio de Torquemada: el edificado por el linaje de los Pimentel ${ }^{33}$. Por el jardín del conde de Benavente pasearon en marzo de 1502 Felipe el Hermoso y su séquito como lo recuerda Antonio Lalaing ${ }^{34}$. También disfrutó de él el infante don Carlos, según el cronista Andrés Muñoz, que acompañó al príncipe Felipe durante su viaje a Inglaterra para casarse con María Tudor: allí escuchó la música que los ministriles tenían preparada para su llegada, se maravilló con las pinturas sobre los trabajos de Hércules que adornaban una de la paredes del jardín, pescó en la alberca llena de barbos, cautivó su olfato el aroma de las rosas y reposó con la frescura que prodigaban las sombras de los árboles ${ }^{35}$. Las noticias de décadas posteriores continúan corroborando el estrechísimo vínculo entre el fasto cortesano y la creación artificial del jardín en el que vengo insistiendo. Antonio de León Pinelo anotaba que el 5 de marzo de 1595, después de que la infanta Isabel Clara Eugenia recibiera la

\footnotetext{
29 A. NAVAGERO, "Viaje por España”, J. GARCÍA MERCADAL (ed.), Viajes de extranjeros por España y Portugal, Madrid, 1952, p. 849.

30 Así lo recoge la relación anónima del Recibimiento de la princesa María en Salamanca viniendo de Portugal a casarse con el príncipe don Felipe, BNM, Mss. 4013, f. 38v: "Llegada pues la princesa aqueste lugar que digo, siendo avisada como el Albadía estaba de allí no más que media legua donde el príncipe había dormido esa noche".

31 L. DE ZAPATA, Miscelánea, BNM, Mss. 2790, f. 49r: "A mayor recreación Aranjuez, a mejor huerta la de la Abadía del duque de Alba".

32 J.C. CALVETE DE ESTRELLA, El felicíssimo viaje del muy alto y muy poderoso príncipe don Phelipe, Amberes, 1552 , f. $3 \mathrm{v}$. El cronista señala varios episodios de festejos o paseos en los jardines a lo largo del viaje del heredero de Carlos V: la visita a la Folía en Bruselas (f. 90), los jardines y arquitecturas efímeras del palacio de María de Hungría en Binche (f. 182 y 200), los jardines que pueden verse desde los barcos al llegar a Génova, las huertas en Heidelberg o el vergel del duque de Arscot en Landresi (f. 181).

33 Me he referido más ampliamente a este jardín en op. cit., 2012. Véase también R. GONZÁLEZ, F. REGUERAS y J.I. MARTÍNEZ, El castillo de Benavente, Salamanca, pp. 86-105.

34 A. DE LALAING, "Primer viaje de Felipe el Hermoso", J. GARCÍA MERCADAL (ed.), Viajes de extranjeros por España y Portugal, Madrid, 1952, p. 452.

35 A. MUÑOZ, Sumaria y verdadera relación del buen viaje que el invictísimo príncipe de las Españas don Felipe hizo a Inglaterra y recibimiento en Vincestre donde casó y salió para Londres, Madrid, 1877, p. 39.
} 
Rosa de oro - una de las más altas condecoraciones vaticanas- que le había enviado el papa Clemente VIII en la capilla del Alcázar real en Madrid, el VI conde de Lemos, Fernando Ruiz de Castro, "llevó a todos los italianos y a otros señores a su casa donde les hizo un gran banquete y después un torneo en el jardín, con que se dio fin a la fiesta" ${ }^{36}$. Aunque no se trata de perseguir más testimonios -que se multiplican a medida que corren los primeros años del siglo XVII-, traigo a colación, sin embargo un último ejemplo, no aislado porque no fueron pocos los jardines efímeros, y que resulta muy sugerente para el espacio estético en el que nos venimos moviendo. Se trata de un jardín artificial, construido como telón de fondo -como un aparato arquitectónico- para la realización de un torneo con motivo de unas bodas realizadas en Zamora durante las fiestas navideñas de 1572 a 1573 . No es extraño que estemos delante de toda una disposición escénica para la celebración de la fiesta ${ }^{37}$, inspirada en algunos de sus tránsitos tanto en la forma como en el contenido en la literatura caballeresca. De nuevo las continuaciones amadisianas de Feliciano de Silva y la saga del héroe llorón, a juicio de don Quijote, de la mano también de otras ficciones literarias, sirven de referente, como sucedería años después con La gloria de Niquea:

"Y estando con mucho silençio los que dentro [del palenque] estavan, súbitamente se cayeron los lienços [...] descubriéndose un jardín, el más admirable que se á visto [...] y prosiguiendo a contar lo que en el jardín a avía, hera desta manera. El jardín estava dos estados de alto sobre las tablas. Avía en él todas las verduras que en semejante tiempo se pudieron pensar ni ynmaginar, todas puestas con tan buen orden, que verdaderamente parecían aver nacido allí, con tantos encañados, yervas y verduras entretexidos, que nadie lo juzgava según su buena horden y delicada postura sino ser, como ya emos dichos, averlos entretexido la naturaleza, abiendo nacido allí los laureles, madroños, naranjos, vices, yedra, siempreverdes, pinos, murtas, arrayanes, cipreses, olivos y otras muchas verduras. Estava en este jardín, quanto dos pasos hazia fuera, un encañado, y tan cubierto de yedra que parecía en extremo bien. Y por el suelo puestos ramos de las mesmas verduras, que parecían árboles que avían nacido allí; y la tierra cavada y levantada, que parecía cabarse para regalo de los árboles, como se suele hazer en los jardines que con mucho cuidado se suelen cultibar. En los cantos deste jardín estavan dos pinos, que verdaderamente parecían naturales" ${ }^{\prime 38}$.

La descripción del anónimo autor de la relación nos remite de lleno a la creación artificial del jardín, a la imitación verista de la naturaleza en un cuerpo escenográfico que retoma los elementos descriptivos de lo que podríamos denominar una poética

36 A. DE LEÓN PINELO, Anales o historia de la villa de Madrid desde el nacimiento de Cristo hasta el año 1658, BNM, MSS/1746, fol. 153r. La noticia también está recogida en la relación Lo que se hizo en el llevar y dar la Rosa a la Señora Infanta doña Isabel, editada como apéndice en "Correspondencia de la infanta archiduquesa doña Isabel Clara Eugenia de Austria con el duque de Lerma”, Boletín de la Real Academia de la Historia, XLIX, 1 (1906), pp. 6-7.

37 P.M. CÁTEDRA GARCÍA, Jardín de amor. Torneo de invención del siglo XVI, Salamanca, 2005-2006, p. 97; remito a sus comentarios e interpretación de la relación de este torneo de invención. Véase también M.R AGUILAR PERDOMO, "La disposición escénica: algunas arquitecturas efímeras en los libros de caballerías españoles", Destiempos. Revista de curiosidad cultural, 23 (2010), pp. 69-103, [http://www.destiempos.com/ n23/aguilar.pdf].

38 P.M. CÁTEDRA GARCÍA, op. cit., 2005-2006, pp. 27-28. 
del jardín: las verduras puestas en buen orden, la réplica de los entretexidos, la presencia de árboles siempre verdes como el laurel, el encañado cubierto de yedra y los pinos que parecían naturales. Pareciera asomarse así una conceptualización de la naturaleza como una realidad construible de manera simulada, una noción que alcanzó su máximo desarrollo en el teatro áureo y que iba de la mano de un designio estético de impronta manierista, acaso relacionado con la importancia que el artificio había cobrado en la mentalidad de la temprana Edad Moderna. El ceremonial caballeresco, realizado aquí en una escenografía superpuesta con aspiraciones de naturaleza verdadera, revela no solo el grado de sutileza y artificiosidad que los animadores de los entretenimientos lúdicos de la nobleza cortesana habían llegado a alcanzar, sino también la importancia que el jardín había adquirido "en las élites españolas como creación artística" ${ }^{39}$. El jardín es objeto de construcción y, por tanto, arquitectura efímera, telón de fondo, al servicio, en este caso, de un ritual caballeresco como el torneo zamorano. Pero el jardín artificial muchas veces sirvió también de decorado de entradas reales y otros entretenimientos cortesanos, en los que el dominio de la naturaleza es un testimonio más del poder simbólico de los más altos estamentos y del desplazamiento de la fiesta a los entornos naturales, reales o - en este caso- figurados. En ese plano se inscriben el conjunto arquitectónico y vegetal del huerto de las Hespérides que se fingió para el recibimiento de Isabel de Valois en Toledo el 12 de febrero de $1560^{40}$. También el programa iconográfico fabricado para la ocasión con madera y cartón piedra, y la alameda artificial que "desde la puente hasta la puerta de la villa [de Béjar] por ambos lados estaba fingida [...] como la verdadera que va de la puente al Bosque" ${ }^{\prime 1}$ en el recibimiento que se ofreció en mayo de 1685 a la X duquesa de Béjar, María Alberta de Castro, cuando fue a tomar posesión de sus estados ${ }^{42}$. En este caso, se creó plásticamente, junto con la alameda fingida, arcos de flores y un arco de triunfo que imitaba un río, un espacio ceremonial que une los jardines del

39 F. PEDRAZA, "De Garcilaso a Lope: jardines poéticos en tiempos de Felipe II", Felipe II. El rey íntimo, Madrid, 1998, p. 327.

40 "Passado de aquí, camino hasta llegar a las casas del Conde de Orgaz, donde en la plaça que delante dellas ay, estava un bosque con mucha diversidad de árboles. Havía laureles, pinos y enzinas, las quales ofrecían a los ojos una aspereza de montaña yerma, con que mucho se levantava el espíritu. De los árboles que más copia avía, ansí en la delantera deste bosque como en la pared de la casa del conde, que de estrota parte de la cavalle estva, eran naranjos con toronjas colgando dellos, porque se fingía ser el huerto de las Hespérides", A. GÓMEZ DE CASTRO, Recebimiento que la imperial ciudad de Toledo hizo a la magestad de la reina nuestra señora doña Isabel, hija del rey Enrique II de Francia, cuando nuevamente entró en ella a celebrar las fiestas de sus felicíssimas bodas con el rey don Filipo nuestro señor, segundo deste nombre, Toledo, 1561, f. $39 \mathrm{v}$.

41 Tomás de Lemus, Relación de la entrada de la excelentísima duquesa doña María Alberta de Castro, Duquesa de Béjar y de Plascencia en su estado de Béjar, Archivo Histórico Nacional (Nobleza), Osuna Leg. 225 , No. 18 , pp. 55-77.

42 Sobre esta entrada y la villa de placer de los duques de Béjar véanse los artículos de A. LÓPEZ ÁLVAREZ, "El jardín, la casa y la fiesta. La construcción de una corte en el ducado de Béjar a fines del siglo XVII", U. DOMÍNGUEZ y J. MUÑOZ (coords.), El Bosque de Béjar y las villas de recreo en el Renacimiento. Actas de las primeras jornadas de estudio, Salamanca, 1994, pp. 97-110; "En torno a la cultura aristocrática del antiguo régimen: fiestas, símbolos y ritos en la entrada a los estados de Béjar, 1685", Estudios Bejaranos, 2-3 (1996), pp. 57-77; y "Espacio, casa e historia en la ideología aristocrática castellana del antiguo régimen", U. DOMÍNGUEZ y J. MUÑOZ (coords.), El Bosque de Béjar y las villas de recreo en el Renacimientos. Actas de las segundas jornadas, Salamanca, 1997, pp. 95-119. 
palacete de recreo con la villa de Béjar y que evidencia que, detrás de la preeminencia del marco natural en la celebración, se manifiesta una intencionalidad estética vinculada con la dialéctica entre la naturaleza y artificio que dominaba por esa época las realidades artísticas de la fiesta y el jardín ${ }^{43}$ (fig. 4).

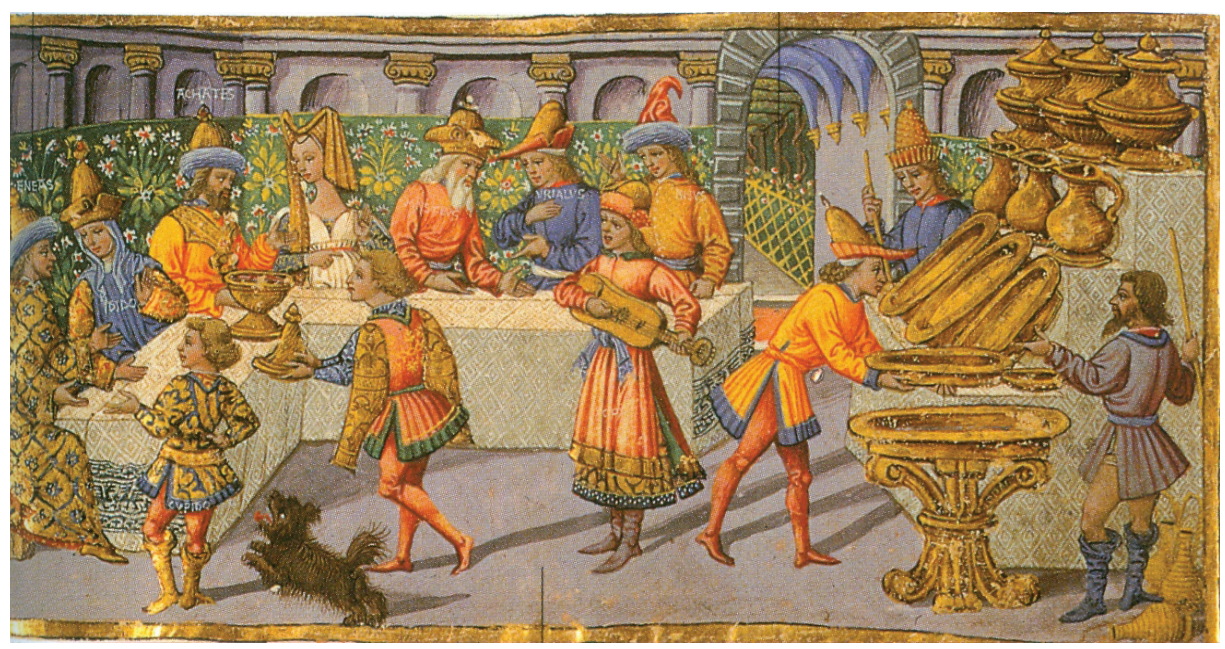

Fig. 4. Apollonio di Giovanni, miniatura del códice de Virgilio, Bucolicon, Georgicon, Biblioteca Riccardiana, sig. ILI.II.1998, f. 75r.

Esa naturaleza construible como jardín artificial, de enormes posibilidades de expresión simbólica, que sirve de espacio escénico a la fiesta cortesana se desdobló también en los pliegos de la ficción pre-cervantina, muy receptiva a las modas y gestos nobiliarios en ese doble camino de influencia que he mencionado páginas atrás. En los libros de caballerías españoles, esos que a su vez impregnaron de maravillas las fiestas cortesanas como la del jardín de Aranjuez o el torneo de zamorano, también se dispusieron jardines artificiales para procurar el entretenimiento y el deleite de los sentidos. Algunos de estos jardines efímeros son preparados expresamente para la celebración de la fiesta en un marco natural, como lo recrea Fernando Basurto en el Florindo (1528), libro en el que se narra la entrada de triunfal del rey de Nápoles en su ciudad tras su triunfo en los torneos de Lorena:

"Dende a ocho días qu'el buen rey partió de Roma con sus cavalleros y gente, arribó a Nápoles, adonde la reina y los ciudadanos le tenían aparejado muy alegre recibimiento por el gozo de las victorias pasadas. El cual fue que hordenaron de poner sobre grandes carros una muy linda huerta proveída de muchos frutíferos árboles y de grandes frescuras en ella, con dos fuentes en medio que por sus caños la regavan, la cual era toda cercada de un rejado labrado. En la cual huerta estavan encerrados muchos venados y corços, y conejos y raposos y otras maneras de animales domésticos,

43 Cfr. C. GÓMEZ LÓPEZ, op. cit., 1999. 
para que cuando el rey y sus cavalleros llegassen a la huerta los soltassen por ella. [...] La cual huerta pusieron fuera de la ciudad, por el camino que el rey había de passar"44

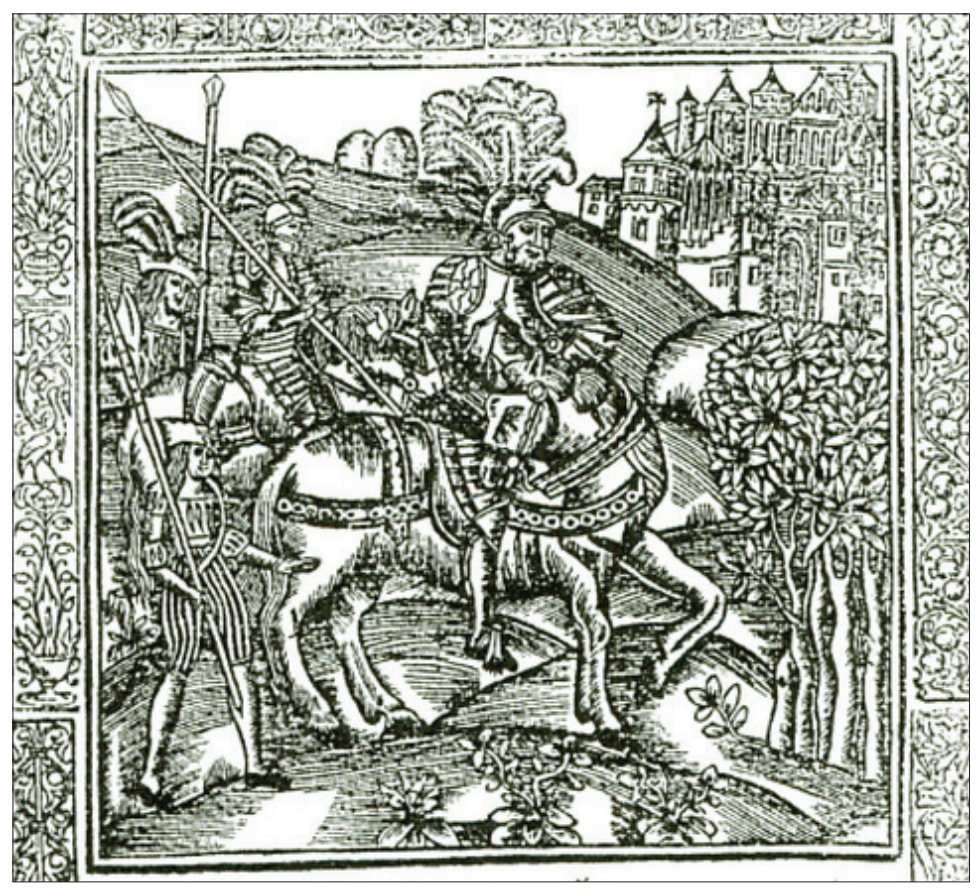

Fig. 5. Portada de la Tercera parte del Florisel de Niquea, BNM, sig. R/2541.

Como ocurre en Jardín de amor, la huerta fingida del Florindo se fabrica recurriendo a los componentes característicos de la ékphrasis del jardín: en este caso se trata de una naturaleza acotada gracias al enrejado labrado que rodea el carro (probablemente un carro triunfal), como un típico locus amoenus cerrado, que, además, tiene árboles frutales, fuentes que vivifican la naturaleza trasplantada al aparato efímero y, finalmente, animales domésticos y de caza, que recuerdan la actividad cinegética tan del gusto de la nobleza aristocrática. La huerta del carro está forjada con tal verismo que, a pesar de su sorpresa porque en "tiempo tan corto se haya hecho cosa tan linda", el rey de Nápoles, "no creía sino ser huerta verdadera y bosque cerrado" ${ }^{45}$; se cumple de esta manera con el requisito fundamental de esa naturaleza construible: la apariencia de realidad que engaña a los sentidos. La doble metáfora de la naturaleza que se abroquela en el jardín artificial confirma aquí el uso de ésta como marco festivo. La lista de textos caballerescos en los que se da dicho uso al jardín es extensa y podría

44 F. BASURTO, Don Florindo, A. DEL RÍO NOGUERAS (ed.), Alcalá de Henares, 2007, p. 202. Para el estudio de las entradas triunfales en el texto véase A. DEL RÍO NOGUERAS, "Dos recibimientos triunfales en un libro de caballerías del siglo XVI", Homenaje a Juan Manuel Blecua, Huesca, 1986, pp. 19-30.

45 F. BASURTO, op. cit., 2007, p. 203. 
multiplicar los ejemplos de caballeros y damas que se refugian en éste para disfrutar de sus saraos. Sobresalen los del Clarián de Landanís -de los que me he ocupado en otro lugar- ${ }^{46}$, y volvemos a encontrar en este inventario al Florisel de Niquea (fig. 5) que no guarda silencio en este aspecto. Un sólo ejemplo, para terminar, de cómo los caballeros literarios también hicieron del jardín territorio de banquetes, música y baile, en este caso en unas fiestas ofrecidas por el rey de Gandes al rey Amadís, sus caballeros y damas:

"El rey Gandes fizo grandes fiestas aquellos señores y señoras, y entre las fiestas que les fizo fue que fizo un combite en un grande y fermoso jardín del palacio a todas las altas dueñas y donzellas de la ciudad, donde todas vinieron, que passavan de trezientas, vestidas muy ricamente a la manera de la ínsula, con estraña hermosura que en todas avía, que por esta causa el rey fizo aquella fiesta, donde por honrarlos salieron al combite la hermosa reina Garaya y la princesa Lucenia, vestidas y tocadas al uso de la tierra de ropas e tocados de tanta riqueza que no tenían precio ni lo tenía su fermosura, de que muy maravilladas fueron las dueñas y donzellas de Gandes y en gran merced les tuvieron el favor de averse vestido a su manera. Y después de aver comido una solemne comida, muchos menestriles entraron, e las donzellas de Gandes dançaron a su uso muchas hermosas danças, y después de aver dançado, ya que noche, a [la] lumbre de muchas hachas antes de la cena la reina Garaya y Lucenia dançaron al uso de Grecia, y por honra[r] la fiesta del rey e mostrar su gracia la reina Garaya e su esposo don Arlanges de España con dos harpas concertadas con sus bozes tañeron y cantaron, teniendo suspensos e maravillados a cuantos los oyeron. Y por más autoridad de la música el emperador Amadís de Grecia les ayudó, y a su petición un romance cantaron que él avía hecho en aquella ínsula donde con Finistea en tanta soledad avía estado con pensamiento de acabar allí e ir a tener compañía a la su Niquea [...] Mas ya que acabada la música, la cena les fue dada con gran magestad y después d'ella uvo mucha fiesta" ${ }^{4}$.

46 M.R. AGUILAR PERDOMO, op. cit., 2010.

47 F. DE SILVA, Florisel de Niquea (Tercera parte), J. MARTÍN LALANDA (ed.), Alcalá de Henares, 1999, p. 442. 